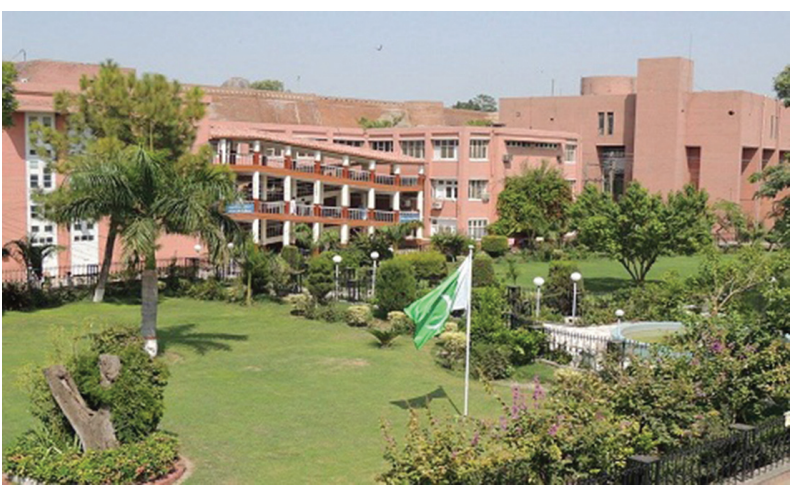

Abstract AB1246 - Figure 1

Conclusions: The idea is to persevere and continue efforts for the betterment of our patients. More specialists are needed to fill in the gaps along with appropriate funding to develop rheumatology services in our part of the country. We feel that situation in other countries with low socio-economics will be more or less the same or even worst for patients with rheumatic diseases. International communities and leagues such EULAR, BSR, ACR and APLAR etc should discuss this on their forums to see if in anyway they can improve lives of millions of people with rheumatic disorders in under-resourced countries.

Disclosure of Interest: None declared

DOI: 10.1136/annrheumdis-2018-eular.2297

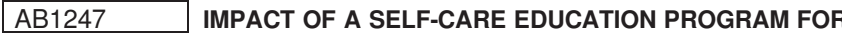 PATIENTS WITH OSTEOARTHRITIS}

A. Gurt ${ }^{1}$, J. Llorente ${ }^{2}$, M. López ${ }^{2}$, L. Tio ${ }^{2}$, B. Sena ${ }^{1}$, F. Montañes ${ }^{1}$, E. Marco ${ }^{3}$ J. Verges ${ }^{4}$, M. Herrero ${ }^{5}$, J. Monfort ${ }^{2}{ }^{1}$ CAP Vila Olimpica; ${ }^{2}$ Rheumatology; ${ }^{3}$ Rehabilitation, Hospital del Mar, ${ }^{4}$ OAFI foundation; ${ }^{5}$ Bioiberica S.A, Barcelona, Spain

Background: Osteoarthritis (OA) has a prevalence rate that reaches $29 \%$ in people older than 60 years ${ }^{1}$. Treatments available are limited. The costs of OA in Spain are about 4.800 million euros/year ${ }^{2}$.

Objectives: To create a self-care program for $\mathrm{OA}$ patients in order to improve their quality of life $(\mathrm{Q} o \mathrm{~L})$ and therefore to reduce the socioeconomic cost.

Methods: The design of the program was carried out by 2 PC physicians, 1 rheumatologist, 1 rehabilitator, 1 nurse and 2 psychologists. The program included a total of 9 sessions of 1.5 hours once a week. There were 2 sessions for each of the following topics: general information, physical activity, nutrition, coping with the disease, and 1 summary session. Three OA patients were trained and afterwards they were in charge of imparting the program to other patients with the assistance of a nurse. Before and after the program some data was collected relating the patients' knowledge, food and physical activity habits, social networks and hours of rest. They were asked to complete WOMAC, EuroQol-5D, and HAD Scale questionnaires. The statistical analysis was performed using package SPSS v16.

Results: 60 Knee OA patients were recruited from Hospital del Mar and Vila Olímpica PC centre, and divided into 6 different groups. Only the results of the first two groups are shown. Group1 (11 patients) and 2 (10 patients). First we analysed differences between the basal data and the ones collected after the last session. The analysis of the data from all the patients (groups 1 and 2) showed that in knowledge about OA management the average value obtained in the basal visit was $6.31 \pm 2.798$, and $7.81 \pm 1.94$ after the last session $(p=0.024)$. Analysis of pain by VAS showed that the average value in the basal visit was $3.91 \pm 1.82$, and 2.44 \pm 2.03 after the last session $(p=0.014)$. We observe a tendency, although it doesn't reach significant differences in QoL, where the average value in the basal visit was $2.31 \pm 1.81$, and $1.63 \pm 1.54$ after the last session $(p=0.052)$. In the HADS scale the average value in the basal visit was $9.86 \pm 6.02$, and $8.36 \pm 5.40$ after the last session ( $p=0.052)$. Regarding the analysis of differences between two groups, categorical items were analysed. In the total questionnaire at the end of the sessions the average for group 1 was 6.89 and for group 2 was $8.75(p=0.038)$. Meeting with friends frequency at the beginning and at the end of the study was also different among groups $(p=0.014 / p=0.019)$.

Conclusions: This self-care education program had a positive effect on the $\mathrm{OA}$ patients pain perception, and it could also be observed an improvement in QoL and the anxiety and depression. As differences among groups were also observed, socioeconomic and education aspects must be considered in the future.
REFERENCES:

[1] Fernandez-Lopez JC, et al. EPISER StudyGroup. Prevalence, risk factors, and impact of knee pain suggesting osteoarthritis in Spain. Clin Exp Rheumatol. 2008;26(2):324-32.

[2] Loza E, Lopez-Gomez JM, et al. Economic burden of knee and hip osteoarthritis in Spain. Arthritis Rheum. 2009 15;61(2):158-65.

Disclosure of Interest: None declared

DOI: 10.1136/annrheumdis-2018-eular.6837

\section{AB1248 VACCINATION RATE IN PATIENTS WITH RHEUMATIC DISEASES: A CROSS-SECTIONAL STUDY IN MEXICAN PATIENTS}

J.P. Carrizales-Luna, D. Galarza-Delgado, J. Esquivel-Valerio, G. Serna-Peña, L. Ramírez-Monterrubio, L. Lozano-Plata, I. Hernández-Galarza, T. GraciaArechiga. Rheumatology, Universidad Autónoma de Nuevo León, Monterrey, Mexico

Background: Patients with rheumatic diseases have an increased risk of infections, which can be prevented with vaccination schemes. The vaccination rate in rheumatic patients is low in Mexico (17\%-25\%), mainly because of the lack of physician recommendation. Vaccination strategies have been shown to improve adherence to the application.

Objectives: The objectives of the study was to determine the vaccination rate in patients with rheumatic diseases and the main reasons of failed vaccination. Methods: We questioned 84 patients from the rheumatology clinic of the Univesitary Hospital "José E. González", Mexico, from June to July 2017. The vaccination status and the reasons for failed vaccination were recorded.

Results: The majority of patients were women (89.3\%), average age 50 years (17-81 years). Most of the patients had rheumatoid arthritis (45.3\%), followed by other autoimmune diseases (27.4\%) and non-autoimmune diseases (27.4\%). The highest rates of vaccination were for tetanus-diphtheria (44\%), influenza (39.3\%) and pneumococcus $(31 \%)$. They were lower for hepatitis B virus $(9.8 \%)$, human papilloma virus (4.8\%), hepatitis A virus (2.4\%) and herpes zoster virus ( $0 \%)$. The main reason for failed vaccination was the lack of indication from the physician $(34.5 \%)$. If indicated, $89.3 \%$ of the patients would accept to be vaccinated.

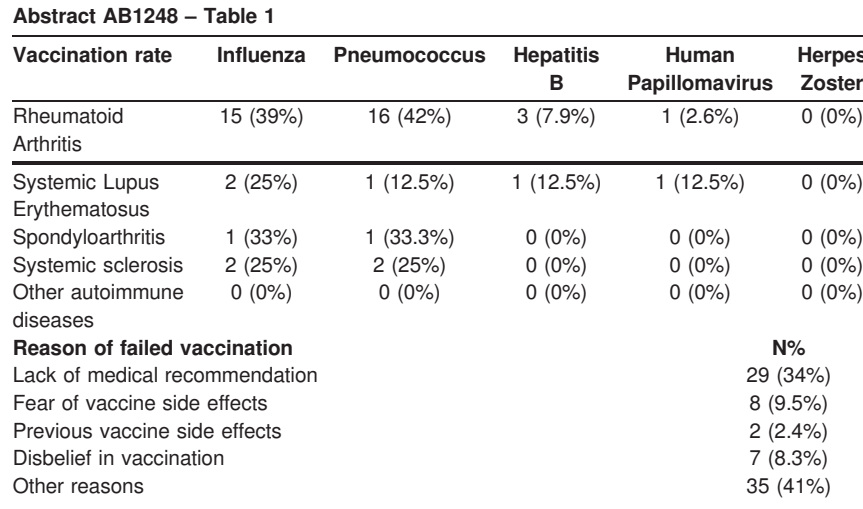

Conclusions: We found a low vaccination rate in the rheumatology clinic. We found an insufficient promotion and indication of vaccination by the rheumatology staff. Constant fomentation and updated knowledge about vaccination recom mendations in autoinmune diseases is necessary for the prevention of infections and to improve the comprehensive care of patients with rheumatic diseases.

\section{REFERENCES}

[1] Garg S. ACR Abstracts. 2016.

[2] Kostantinos T \& Vassilopoulus D. Best Practice \& Research Clinical Rheumatology xxx (2016) 1e18.

[3] Black S, et al. ACR Abstracts. 2011.

[4] Bühler S, et al. Swiss Med Wkly. 2015;145: w14159

Disclosure of Interest: None declared

DOI: 10.1136/annrheumdis-2018-eular.6092 